\title{
Hospital nurses working wounded: Motivations and obstacles to return to work as experienced by nurses with injuries
}

\author{
Kathleen Mullen ${ }^{\mathrm{a}, \mathrm{d}, *}$, Marion Gillen $^{\mathrm{c}}$, Susan Kools ${ }^{\mathrm{a}}$ and Paul Blanc ${ }^{\mathrm{b}}$ \\ ${ }^{a}$ School of Nursing, University of California, San Francisco, CA, USA \\ ${ }^{\mathrm{b}}$ School of Medicine, University of California, San Francisco, CA, USA \\ ${ }^{\mathrm{c}}$ University of California, Berkeley, CA, USA \\ ${ }^{\mathrm{d} D o m i n i c a n}$ University of California, San Rafael, CA, USA
}

Received 11 September 2012

Accepted 23 September 2013

\begin{abstract}
.
BACKGROUND: Despite the high rate of work-related injuries among hospital nurses, there is limited understanding of factors that serve to motivate or hinder nurses return to work following injury.

OBJECTIVES: Perspectives of nurses with work related injuries, as they relate to obstacles and motivations to return to work, consequences of injury, and influences of work climate were documented.

METHODS: This was a sub-study of nurses taken from a larger investigation of hospital workers. A purposive sample of 16 nurses was interviewed. Analysis was carried out using grounded theory as the research method.

RESULTS: Nurses' responses fell into four concepts: organizational influences, personal conditions, costs and losses, and employee health as influenced by workers' compensation systems. Conceptualization of these concepts resulted in key categories: injury as an expected consequence of hospital work; nursing alone versus nursing together; the impact of injury on professional, family, and social roles; and nurses' understanding of and involvement with the workers' compensation system.

DISCUSSION: The findings provide new perspective into features that support or hinder nurses' with injuries return to work and corroborate existing occupational health research. Consideration of these findings by hospital and employee health managers may help promote more effective return to work programs within the hospital setting.
\end{abstract}

Keywords: Grounded theory, work injury, hospital work climate, hospital nurse, return to work

\section{Introduction}

Nurses have one of the highest rates of work-related musculoskeletal injuries of any professional group and, unlike others, have not shown a decline in injury over the past decade, primarily due to the demands of patient care handling [1]. In 2011, registered nurses in

\footnotetext{
*Corresponding author: Kathleen Mullen, 1215 Idylberry Road, San Rafael, CA 94903, USA. Tel.: +1 415971 6466; E-mail: Kathleen.RN@gmail.com.
}

the US were among the five occupations with more than 11,000 reported musculoskeletal injuries necessitating time away from work. Other groups included nursing assistants, laborers, janitors and cleaners, and heavy truck drivers [2]. Nurses in hospital settings often are required to work rapidly as they handle awkward, unpredictable lift loads in crowded spaces occupied by sick patients and varying types of equipment. Due to these workplace demands, injury is an expected consequence of work for many nurses who provide direct patient care $[3,4]$. Despite the risk, many nurses enter the profession because of the deeply per- 
sonal rewards and identity they experience providing patient care [5]. Work-related injuries can jeopardize an individual's work and health temporarily, if not permanently [6,7]. Despite the frequency of injuries to nurses, we have limited understanding of the motivations and obstacles to return to work and continued work following injury to hospital nurses. It is important to gain a better perspective on the nurse's experience of injury and disability to counterbalance the existing literature, which focuses primarily through the lens of lost income, debt, physical function, and other quantifiable parameters [6-8]. The social, family, and workplace consequences of injury can only be understood from the perspective of the worker who has been injured by allowing that worker to articulate the experience in his or her own words [10-12].

The purpose of this study was to explore the experiences, perceptions, and consequences of being nurse with an injury. Specific aims were to:

1. Describe the subjective meaning of work injury and loss of ability and its full impact on nurse's life post-injury.

2. Understand the influences of work climate on the nurse's experience post-injury.

3. Identify motivational and/or obstructive influences on work for nurses after injury.

This analysis describes and explains the motivations and obstacles to work for the nurse after experiencing a work-related injury.

\section{Methods}

The research aimed to capture a range of contextual meaning acquired from experiences, interactions, and beliefs that may motivate or inhibit hospital nurses return to work and continued employment after injury. Therefore, grounded theory methodology was used to identify the realm of experiences involved in the phenomenon.

\subsection{Sub-study design and sample}

This research project, entitled Motivations and $\mathrm{Ob}-$ stacles to Employment for Injured Hospital Nurses (MORE Nurses study) was a sub-study of the multidisciplinary, longitudinal study, Gradients of Occupational Health in Hospital Workers (GROW). The GROW study used quantitative and qualitative methodologies to study hospital workers from two separate urban hospitals in northern California. Participates for the GROW study were recruited following a reported acute or cumulative work-related musculoskeletal injury. Non-injured hospital employees were matched for comparison to cases in the injured group, either by job group, work shift, or as a random incidence match (e.g., three to one matching overall) [13-16].

Of the 243 nurse participants from the original GROW study, a purposive sample of 32 nurses who were responsible for direct patient care were selected for recruitment into the MORE Nurses study. Because the focus of the MORE Nurses study was on work injury experiences of hospital nurses, GROW nurse cases with reported injuries were introduced to the study by mail. Participants were initially recruited by mail (two mailings); those who did not decline were then contacted by telephone for consent to interview. Sixteen nurses $(50 \%)$ agreed to participate. Six nurses declined to participate due to lack of time and 10 could not be contacted.

The Committee for Human Research at the University of California, San Francisco, approved the study.

\subsection{Data collection procedures}

Individual, face-to-face or telephone interviews were conducted in mutually agreeable locations that allowed for privacy and confidentiality. A question guide, using open-ended interviews intended to address the study aims, was used while allowing participants the freedom to generate their own descriptions of work-injury experiences [Appendix 1]. All nurse interviews were conducted by the same researcher (first author). Nurses were asked to describe both their direct experiences as well as their perspective of working with nurse coworkers who had also been injured. Data gathered from participant interviews were expected to be rich with description, revealing thoughts, feelings, intentions, and actions [17]. In addition to the interview, participants were asked to complete a single-page demographic questionnaire.

Interviews were recorded and transcribed verbatim. The recordings and transcripts were compared to ensure the most complete and accurate transcript possible. Interviews were labeled to remove all identifying information from interview transcripts.

\subsection{Data analysis}

Maintaining grounded theory methodology, the analytic processes were sequential, methodical, and highly structured [17]. Analysis of the interview data was con- 
current with the ongoing interviews and helped formulate the direction of subsequent interviews based on emerging data. Interview transcripts, field notes, and memos generated during the process were included in the analysis.

Key operations of grounded theory were adhered to, including levels of coding, conceptual memo writing, theoretical integration, and verification [17]. Analysis began with line-by-line open coding of each interview transcript and continued throughout the process of writing the results. Coding was done sequentially by the interviewer and regularly reviewed by coresearchers in the group (authors 2-4). As the process of coding continued with subsequent interviews, some codes began to repeat across different narratives. These more salient codes were merged into thematic categories and organized into tables to express the range of variation in each category. These consolidated groups of codes became the foundation of the emerging concepts that led to an integration of conceptual motivations and obstacles to work for nurses (see Table 1).

To check the rigor of analytic procedures and verify conceptualizations, ongoing feedback on the products of analysis was obtained from a highly qualified grounded theory researcher and frequent meetings with an experienced qualitative research group. Member checks were not performed, however, co-investigators with expertise in workers with injuries reviewed analyses and findings for credibility.

\section{Results}

\subsection{Sample characteristics}

The 16 participants were all women, with a mean age of 51.5 years $(\mathrm{SD}=7.4)$. The mean number of years since $\mathrm{RN}$ licensure was $24(\mathrm{SD}=8.0)$. Nine were born in the US and 12 received their nursing education in the US. One participate was trained in Canada, another in Ireland, and two in the Philippines. Participants were actively engaged in direct patient care in a variety of hospital units, in two large community-based urban medical centers. All participants interviewed had reported a work-related musculoskeletal injury, however, all nurses had previously returned to work by the time of the interview. One participant relocated during her recovery therefore, returning to work at an alternate hospital; all others returned to the same hospital where they had sustained the injury. Data regarding the specific injury, length of time off work, and time be- tween injury and return to work were not systematically collected, though the particular injury, recovery, and return to work experiences were discussed in the interviews.

\subsection{Organizational and personal conditions of the nurse injury experience}

Through the use of grounded theory methodology, preliminary concepts emerged from the coded data to describe contributions to the injury experience as well as explain motivations and obstacles to work for participants including: organizational influences, personal conditions, costs and losses, and employee health as influenced by the workers' compensation system. These were further refined resulting in the following four key conceptual categories: injury as an expected consequence of hospital work; nursing alone versus nursing together; change in professional, family, and social roles; and help/hindrance of workers' compensation system participation (Table 1). The findings for each of these categories are described in greater detail below.

\subsection{Organizational influences}

These hospital nurses who provide direct patient care described a physically and emotionally demanding work environment. At the same time, many participants indicated a conscious choice in selecting their particular workplace, "I wouldn't want to work any place else," because of a desire to work with the diverse patient population found in these large urban teaching hospitals. Many participants had worked as nurses for more than twenty years in the same hospital. Participants also described their workplace as one with ever evolving policy and procedures: "There is always somebody doing a research project - there's always something new." In a workplace that was considered professionally stimulating and dynamic, one nurse said with pride, "It's where I learned to be a nurse".

In a fast paced hospital setting, nurses described work routines that required them to push themselves beyond their physical limits in order to complete their assignments, sometimes creating unsafe conditions for themselves such as pushing a hospital bed from one unit to another without assistance or underestimating the need for help when doing routine procedures on a patient whose behavior was unpredictable. Nurses actively engaged in providing direct patient care tended to minimize the risk of injury as a consequence for 
Table 1

Categories of motivation and obstacles to work for nurses after injury

\begin{tabular}{ll}
\hline Concept & Conceptualized category \\
\hline Organizational & Injury as an expected consequence of hospital work \\
Cowfluences & Nursing together \\
& Fractured workforce, divisive influences of support \\
& Fear of the consequences of injury \\
Personal & Working wounded \\
conditions & Shame related to changes in their family and social roles \\
& Self-treatments and protections the impact of desensitization \\
& Jeopardized financial security and future goals: family and self \\
Costs and Losses & Role Loss \\
& Too great a cost: the nurse's choice to avoid benefits \\
Employee Health as & Help or hindrance: the cost to one's integrity \\
Influenced by Workers & When workers cannot return \\
Compensation System & .
\end{tabular}

work: "I was so exhausted one night I actually stuck myself three times with the same needle." She then admitted that she had not reported any of the needle sticks she sustained that shift. Awareness of the organizational demands along with the individual nurse's desire to provide care created an environment where nurses put the needs of patients before their own.

I never really took it seriously how easy it is to injure yourself when you're turning a 400 pound patient or whatever you're doing... for 12 hours a day.

I was trying to put in an IV and suddenly the patient caught my hand and twisted my arm... it was excruciating pain.

As nurses focused on patient care demands, many described recognizing they had been injured only after their work pace slowed, often at the end of their shift, rather than by a particular mechanism of injury that interrupted their workflow.

I didn't report it, I wasn't even that badly injured, but I remember it so distinctly... when I left work I thought I was going to die if I couldn't sit down and get off my feet.

...just strain, just strains, fortunately. I'd come home knowing it was just a strain, thinking I'd have to be careful.

It was just a strain, but I kind of freaked out. I mean it was incredibly painful. I went home took some Advil $^{\circledR}$ and went to sleep.

Many participants were very descriptive, even passionate, as they detailed how valuable coworker support is to their job satisfaction and success in the work they do. Some nurses described their hospital unit as "family." Conversely others voiced feeling isolated be- cause the nurses on their unit did their work as if nursing was "just a job."

Engagement as described among nurses, which indicated a shared philosophy of caring, was repeatedly reported as a primary motivation to work for hospital nurses. What these nurses describe is an enthusiasm gained from nursing together with other nurses who share their work ethic of nursing values and commitment. Nurses recognize these traits in others as a shared view of meaning for the work they do which creates a strong bond. One nurse described her coworkers as "war buddies."

You rely on the people you work with... And they rely on you... you need each other. So you appreciate each other for what they give you and for what you give them and there's a sort of camaraderie.

... you cannot "nurse" alone.

There's the feeling that the experience is shared only among people you work with... And so there's this sort of unspoken understanding that what you share, that brings you closer together with the people that you work with, that forms a tie that is very special.

The nature of hospital nursing is physically demanding due to a variety of factors, including patient rooms cramped with machines, the weight and size of bariatric patients, and limited support staff. The nurses in this study worked twelve hour shifts; many commuted more than one hour each way from home to work. Several reported trying to nap in shared lunch rooms or the hospital meditation room during their breaks. Although many nurses gave credit to those they work with for willingly reciprocating support and sharing the workload, they also recalled situations when support was not available. As they readily describe a 
work environment where hospital nurses do their best to carry out their work assignments, they also acknowledge the frequency and the under-reporting of workplace injuries; in other words, a hospital unit where nurses are not only fatigued from the work, but are also "working wounded." These wounded nurses are, therefore, less available to help coworkers and in fact, require the assistance of others themselves.

I've had those days where I've thought, who hasn't had back surgery? Or who hasn't been recently hurt?" Or who can I ask who isn't pregnant? And I think... this isn't going to be a good day...

For injured hospital nurses, coworker support was reported as a significant factor in helping them maintain work. Without it, nurses were hindered by feeling that they were nursing alone, which for a nurse with an injury became an obstacle to completing the work assignment. In addition to nurses who work while injured, the mix of temporary and regular nurses assigned to the unit influenced the cohesiveness experienced among workers, particularly when units had high numbers of non-permanent "travel" nurses. Travel nurses, who travel from hospital to hospital for designated timeframes (usually 13 weeks) were seen as skilled, but not invested in the workplace. This lack of investment created a greater burden on regular staff who, by default, are responsible to participate in such things as hospital committees, staff training, and development of unit policy. When hospital units relied heavily on temporary staffing, nurses experienced this as obstruction to their workflow and patient assignments, as well as divisive to nursing together.

The core staff orients new staff travelers to the unit and basically... I feel you're talking, but they're not listening. I always think they're not as invested so they kind of don't really care. They're nurses, they've been many places, and they know the work. So they just kind of tune you out.

It would make a difference if there were more regular people because the core staff takes on a tremendous burden and lot more responsibility.

\subsection{Personal conditions}

Participants discussed a strong commitment to being a nurse as an intentional choice. Several expressed being inspired by an admired family member, often having a mother, sister, or brother who is a nurse, as if being a nurse was a way they fit within their family.
I feel very privileged. You get to be with people being born, and people dying, those who are sick and those with your care... get better.

An aunt of mine is a nurse. That's how I became interested... I looked up to her, she was my role model.

My mother wanted to become a nurse but she had to quit school in tenth grade to work. So I became a nurse.

The nurses described themselves as helpers both at work and in their family role. Several participants gave accounts of being the medical resources, if not the family caretaker for family members. When asked about the consequences of a work injury, nurses voiced fear of loss that a work injury could jeopardize their identity as a nurse.

I thought, oh my god, I'm going to be out of nursing. This could end my career. That's when I decided to go to graduate school.

When my mom got sick, she was very agitated, you know what I did? Gave her a bath... washed her hair...that's it! That is the essence of nursing. I'm very proud of it.

A personal characteristic reported by nurses was their resourcefulness in managing their own medical needs, sometimes in lieu of obtaining a complete medical evaluation for a work injury. Participants repeatedly described situations where they self-assessed, self-diagnosed, or self-treated their work injuries. One nurse with chronic upper extremity pain sought selftreatment measures in order to maintain her work demands, after she had been discharged from care by employee health (that is, had returned to work and had no access to further medical follow-up).

I just asked the physical therapist at work. I figured there was something more I could be doing or at least things I could be avoiding. And, you know, being at the hospital you're sort of surrounded by resources.

\subsection{Costs and losses}

In addition to loss of personal identity, nurses with injuries expressed fear of financial loss as a motivation to work because many contributed equally or were primary breadwinners for their families. In addition, because hospitals provide good benefits, many were their family's sole source of health insurance. With insufficient secondary resources, even a temporary gap in income can have disastrous family consequences. 
It would be a nightmare. I've got an incredibly expensive mortgage. It would be a nightmare. I don't know what I'd do... I don't even want to think about it... I would lose my house.

I am the primary breadwinner for my family and provide our health insurance...

In addition to lost resources, nurses revealed a personal loss associated with a shift in family role following limitations from a work injury, even when they were able to maintain their work duties. Nurses who had been injured were motivated to work because of a feeling of dedication and a desire to keep their job, did so despite enduring personal obstacles at home. Nurses who pushed themselves to maintain their work duties, reported being ashamed that their family suffered because they could not maintain their regular physical demands at home.

I try to take it as easy at home. For instance, yesterday at work, I was getting sore and today it's pretty sore. So you know... I don't do heavy thing like carry grocery bags. . . But I just saw the doctor. And I got discharged from treatment and cleared to do my full workload.

I'm on the job, but my husband does the cooking even though he has a very long day and my son does the laundry... he's only 10 years old, I feel bad about that.

\subsection{Employee health as influenced by the Workers' compensation system}

Nurses who sustained injuries were not motivated to access support from the workers' compensation system following a subsequent injury. In fact, nurses who perceived the system as an obstacle to maintaining their role identity and integrity, made a conscious decision not to report some injuries to their employer. Lack of reporting was motivated by fear that they would be forced to accept a demeaning light duty position within the hospital. Nurses admit injury is commonplace, so they developed informal "work-arounds" in order to stay on the job, thereby remaining hidden from the hospital's employee health system. For example, one nurse reported that she traded patient assignments with other staff rather than report that she had limitations due to a musculoskeletal injury that restricted her from working with bariatric patients.

For many nurses, a factor in injury reporting had to do with how well symptoms resolved with time off between shifts. If they got better with self-assessment and treatment, the nurse considered the injury incidental rather than reportable. For example, one nurse did not consider her back injury worth reporting because it had not "stopped" her from coming to work every day and accepting her regular assignment. However, when asked whether she felt more vulnerable to further injury after sustaining an initial injury, regardless of reporting, she reported that the injury event left her fearful of the consequences of a subsequent injury.

Oh absolutely... I mean, I'm still aware that such an assault on your back doesn't go away.

As expected in a setting where nurses minimize their own needs and even accept injury as a consequence of work, lost time from work was not reflective of the number of injuries experienced. One nurse who had been injured, who also shared responsibilities as a unit leader, described her setting as one where injury to staff nurses was "pretty frequent." She went on to say that it was "pretty rare" that those same nurses with injuries actually took time off from work.

After reporting a work injury, one nurse vowed she would only do so again as a last resort. She described the experience as "horrifying." Many nurses refused to report their injuries because of a strong desire to avoid light duty work assignments based on their own prior experience or that of a coworker.

Maybe if I had a really bad injury and could not work at all I would apply for benefits, but only if I could not work anymore.

I'm not going on disability again...doing light duty, I can't do that work. I felt thrown to the wolves being assigned to different areas of the hospital.

Not too long ago, I probably pulled something and I reported it right away [because it was witnessed]. When they [employee health] called me, I said, 'I feel much better.' I didn't want to have deal with them again. Doing light duty job... if I am really, really injured I think that's the only time I would. I won't do that light duty.

The decision to minimize and even refuse to report an injury to employee health was based on a feeling they would be forced to accept meaningless work or work they did not have the adequate skills for which, if refused, meant no work and therefore, lost wages. The nurse explained that light duty often meant being assigned to a clerical job anywhere in the hospital rather than anything related to patient care.

All nurses reported a lack of understanding of the benefits covered by workers' compensation. Nurses' 
claims for benefits post-injury, under the no-fault system of workers' compensation, are sometimes investigated to determine entitlement. When the legitimacy of claims for compensation benefits were imposed on nurses "working wounded," one nurse perceived the investigation as a challenge to her integrity and honesty.

Yeah, somebody came in here and interviewed me! I don't know about other people because I haven't even talked about it. . . but I just feel like... man, I mean, I'm not lying about my injury. If I was. . . and if I was that lazy, why would I have come back to work?

The fact that the nurse's claim was investigated while she was struggling to maintain her work pace not only made no sense to her, it caused her public embarrassment because she had purposefully kept information about her injury private to avoid being talked about by coworkers.

Most nurses were aware of the hospital employee health department and injury reporting system; however, they had a fragmented understanding of the workers' compensation benefits available to them. The full extent of benefits often was unknown, but most believed benefits included medical treatment and salary continuance if unable to work: "I think they give you your salary and medical care." Several nurses proudly reported paying for private disability insurance so they could avoid using the workers' compensation system if they were injured.

Regardless of benefits available to nurses through the employee health department and the workers' compensation system, permanent job loss does occur. All participants had direct knowledge of a coworker who was no longer at work due to an injury. When a valued nurse coworker sustains a career ending injury and does not return to work, it is experienced as a significant personal loss by the staff and a reminder of their own vulnerability. Employee health was seen as an extension of hospital administration. When a long time, valued nurse coworker is unable to return after a work injury, the perception is that the hospital administration lacks value for the person and respect for the risk of injury bedside nurses experience.

I feel like there are many of us that are just another injury away from not being able to return. I have worked with one nurse that could not return to bedside nursing and the other one I'm very afraid might not because she had a severe enough injury. I worry about that last injury that takes her away from bedside. I think it would be great loss.
I really regret there was no announcement about her leaving, we didn't have a party... she just faded away. If she had retired, we would have had a party. As hard as you work, as much as you give to the institution, you're just thrown away.

\section{Discussion}

The organizational and personal conditions described here represent experiences that motivate and obstruct hospital nurses to return to work after an injury and continue at the job. Overall, a shared professional engagement and identity with nurse coworkers emerged as a strong source of motivation to participants who described a willingness to overcome obstacles associated with the physical and emotional demands of their workplace, changes in family role, and benefits of employee health and workers' compensation.

In this study, hospital nurses freely articulated their experiences of work-related injuries and their aftermath. Their words described the role that injury played on themselves, their coworkers, and workflow on the hospital unit. Most of the nurses admitted to working while injured and several made a conscious decision not to report their injury.

These findings identified a range of motivational factors that influenced nurses' work ability following injury, such as trusted and deep relationships with coworkers, unique demands and rewards of hospital nursing, and a shared role identity with family and other nurses, which were experienced collectively as nursing together.

Yet findings also identified obstacles to productive work that could not be overcome by nursing together. Issues including a work climate where injuries are commonplace and expected, a workforce staffed by temporary nurses, and an overall misunderstanding of the workers' compensation system, emerged as common sources that contributed to nurses feeling they had little choice but to cope with long shifts and work assignments while working wounded. Unable to maintain both their hospital duties and personal chores, many nurses shifted responsibilities at home to others in the family.

These findings support and expand existing occupational health research that describes the personal and social consequences of work injury, including loss of role identity at work and home, mistrust of the workers' compensation system, lack of injury reporting, and fear of re-injury $[8,9,18-20]$. 
Workplace challenges, including chronic fatigue, injury risk factors, and the effects of staffing with temporary nurses consistent with other research findings [2123] were also voiced by nurses in the MORE Nurses study. Like other groups of workers, nurses reported difficulty performing their job duties even once they had been released to full duty [24,25]. Frequent reports of fears of a career ending injury and, at the same time, reluctance to access care (including reinjury prevention assistance) from the hospital's employee health department make the prevention of further injury problem-ridden.

The practice of returning to work with a persistent injury, which repeatedly emerged in this study, has implications for obstructed workflow and reduced productivity across the nursing unit. Nurses who continue to work after injury are at greater risk for re-injury and limited in the work functions they can safely perform. Furthermore, the inability of nurses with injuries to assist other nurses on the unit places a greater burden on non-injured nurses, potentially increasing their risk for injury and straining their ability to complete their tasks.

Overall findings from this study provide insight into the health and safety of working hospital nurses and offer areas for improved support in their effort to carry out patient care assignments. Knowledge gained from the MORE Nurses study includes vivid experiences associated with accessing workers' compensation benefits, light duty work assignments and changes in social role. Moreover, this pattern of findings should be investigated for its generalizability to other health care professionals.

Because so many nurses experience injury, finding ways to promote collaboration between hospital employee health departments and staff nurses, aimed at meaningful short term work assignments that recognize the importance of role identity would provide working wounded nurses more visibility to employee health services, while reducing the hidden strain of other nurses on the unit. For those nurses unable to return to work, finding ways to recognize their contributions would be valuable to them and the remaining staff nurses.

\subsection{Limitations and strengths}

Characteristic of qualitative research, each participant was provided extensive confidential interview time to express their individual experiences and observations as narrative. While the participants' index injury facilitated inclusion in the GROW study, their boarder injury experience described here, provided added depth to their previous responses.

Limitations include small sample size and substudy design that did not allow for theoretical sampling typical in grounded theory methodology. Selection of a purposefully diverse sample among eligible nurses was attempted to reduce this limitation. Enrolling nurses from two different hospitals expanded the understanding of workplace influences. The findings were strengthened by verification with a highly experienced grounded theorist, as well as substantive experts who reviewed the data, key concepts, and conceptualization that sought to address the study aims.

\subsection{Practical implications}

Gaining a deeper understanding of what motivates and inhibits nurses to work after an injury will allow hospital employee health departments to better design and implement practices that recognize the value of employees. Reducing under reporting of work injuries that result from poor experiences with injury investigation and light duty assignments will insure a healthier workforce of nurses available to provide patient care.

\section{References}

[1] Nelson A, Matz M, Chen F, Siddharthan K, Lloyd J, Fragala G. Development and evaluation of a multifaceted ergonomics program to prevent injuries associated with patient handling tasks. Int J Nurs Stud. 2005 Oct 24;(43):717-733.

[2] http://www.bls.gov/news.release/osh2.nr0.htm; downloaded Jan 20, 2013.

[3] Stone PW, Mooney-Kane C, Larson EL, Horan T, Glance LG, Zwanziger J, et al. Nurse working conditions and patient safety outcomes. Med Care. 2007 Jun;45(6):571-8.

[4] Trinkoff A, Le R, Geiger-Brown J, Lipscomb J, Lang G. Longitudinal relationship of work hours, mandatory overtime, and on-call to musculoskeletal problems in nurses. American Journal of Industrial Medicine. 2006;49(11):964-71.

[5] Raatikainen R. Nursing care as a calling. J Adv Nurs. 1997 Jun;25(6):1111-5.

[6] Charmaz K. Loss of self: A fundamental form of suffering in the chronically ill. Sociology of Health \& Illness. 1983 1983/7;5(2):168-95.

[7] Pransky G, Benjamin K, Hill-Fotouhi C, Himmelstein J, Fletcher KE, Katz JN, et al. Outcomes in work-related upper extremity and low back injuries: results of a retrospective study. American Journal Of Industrial Medicine. 2000 2000/4;37(4):400-9.

[8] Keogh JP, Nuwayhid I, Gordon JL, Gucer PW. The impact of occupational injury on injured worker and family: outcomes of upper extremity cumulative trauma disorders in Maryland workers. Am J Ind Med. 2000 Nov;38(5):498-506. 
[9] Morse TF, Dillon C, Warren N, Levenstein C, Warren A. The economic and social consequences of work-related musculoskeletal disorders: the Connecticut Upper-Extremity Surveillance Project (CUSP). International Journal Of Occupational And Environmental Health: Official Journal Of The International Commission On Occupational Health. 1998; 4(4):209-16.

[10] Strunin L, Boden LI. The workers' compensation system: worker friend or foe? Am J Ind Med. 2004 Apr;45(4):338-45.

[11] Sum J, Frank J. Return-to-work in California: Listening to stakeholders' voices: Commission on Health and Safety and Workers' Compensation, Institute of Industrial Relations, University of California, Berkeley 2001 July 2001.

[12] Strunin L, Boden LI. Family consequences of chronic back pain. Social Science \& Medicine. 2004 2004/4;58(7):138593.

[13] Gillen M, Yen IH, Trupin L, Swig L, Rugulies R, Mullen K, et al. The association of socioeconomic status and psychosocial and physical workplace factors with musculoskeletal injury in hospital workers. Am J Ind Med. 2007 Apr;50(4):245-60.

[14] Gordon DR, Ames GM, Yen IH, Gillen M, Aust B, Rugulies $\mathrm{R}$, et al. Integrating qualitative research into occupational health: a case study among hospital workers. J Occup Environ Med. 2005 Apr;47(4):399-409.

[15] Janowitz IL, Gillen M, Ryan G, Rempel D, Trupin L, Swig L, et al. Measuring the physical demands of work in hospital settings: design and implementation of an ergonomics assessment. Appl Ergon. 2006 Sep;37(5):641-58.

[16] Rugulies R, Braff J, Frank JW, Aust B, Gillen M, Yen IH, et al. The psychosocial work environment and musculoskeletal disorders: design of a comprehensive interviewer-administered questionnaire. Am J Ind Med. 2004 May;45(5):428-39.

[17] Charmaz K. Grounded Theory. In: Smith JA, editor. Qualitative Psychology: a practical guide to research methods: Sage Publications; 2003.

[18] Biddle J, Roberts K, Rosenman KD, Welch EM. What percentage of workers with work-related illnesses receive workers' compensation benefits? J Occup Environ Med. 1998 Apr; 40(4):325-31.

[19] Dembe AE. The social consequences of occupational injuries and illnesses. Am J Ind Med. 2001 Oct;40(4):403-17.

[20] Pransky G, Snyder T, Dembe A, Himmelstein J. Underreporting of work-related disorders in the workplace: a case study and review of the literature. Ergonomics. 1999 Jan;42(1):171-82.

[21] Aiken LH, Clarke SP, Sloane DM. Hospital staffing, organization, and quality of care: Cross-national findings. Nurs Outlook. 2002 Sep-Oct;50(5):187-94

[22] Clarke SP, Sloane DM, Aiken LH. Effects of Hospital Staffing and Organizational Climate on Needlestick Injuries to Nurses. Am J Public Health. 2002 July 1, 2002;92(7):1115-9.

[23] Trinkoff AM, Le R, Geiger-Brown J, Lipscomb J, Lang G. Longitudinal relationship of work hours, mandatory overtime, and on-call to musculoskeletal problems in nurses. Am J Ind Med. 2006 Nov;49(11):964-71.

[24] Cheadle A, Franklin G, Wolfhagen C, Savarino J, Liu PY, Salley C, et al. Factors influencing the duration of workrelated disability: A population-based study of Washington State workers' compensation. American Journal Of Public Health. 1994 1994/2;84(2):190-6.

[25] Keogh JP, Gucer PW, Gordon JL, Nuwayhid I. Patterns and predictors of employer risk-reduction activities (ERRAs) in response to a work-related upper extremity cumulative trauma disorder (UECTD): reports from workers' compensation claimants. Am J Ind Med. 2000 Nov;38(5):489-97.

\section{Appendix 1: MORE Nurses Study: Interview question guide and topic prompts for injured nurses who have returned to work}

\section{Topic Prompt: meaning of being a nurse}

1. This study is aimed at learning more about nurses who have been injured on the job. Before we talk about your injury, I'd like to learn about you as a nurse. So first, tell me about yourself.

- work history

- education and professional memberships

- family influences

- meaning of nursing: job, career, calling -give me an example of what you mean

Topic Prompt: the when and how of injury

2. Now I'd like to learn about your injury experience. Tell me about your initial injury experience and how it progressed.

- response of co-workers, supervisors

- medical treatment

- workers' compensation

- an example of a specific event that that describes your experience

Topic Prompt: roles beyond nursing/work-life balance issues

3. Now I would like to learn about the effects of your injury on your life outside work. How would you describe the effects of this injury on your personal life?

- immediate family

- family support

- shift in household chores

- social life and work friends

- change in hobbies and volunteer work

* self identity and self image

* give me an example of a specific situation that describes the impact on you life outside work. 


\section{Topic Prompt: influences of work climate}

4. I am aware that most people who have a work injury go back to work whether or not they have fully recovered. One thing that interests me is how your work environment might influence your being off work and your efforts to return to work.

- sources of support on the job

- staffing

- light duty assignments

- continuing contact with co-workers

- influence of others on return to work

- who decided on the timing of your return to work

- give me an example of how your work setting has impacted your return to work

\section{Topic Prompt: coworker influences}

5. Now I would like to know if you have worked with other nurses who have had work injuries. If yes...

- influence on your work duties

- contact with injured co-worker

Topic Prompt: open to anything participant wants to add

6. Is there anything else about your experience of having a work injury or your effort to return to work that I have not asked that you think I should know? 